\title{
EFEITO DA APLICAÇÃO DE PÓ DE BASALTO NO DESENVOLVIMENTO INICIAL DE MUDAS DE CAMU-CAMU (Myrciaria dubia) ${ }^{1}$
}

\author{
MARINA KEIKO WELTER ${ }^{2}$, VALDINAR FERREIRA MELO ${ }^{3}$, CLÁUDIO HORST BRUCKNER ${ }^{4}$, \\ HELEN THAÍS PEREIRA DE GÓES ${ }^{5}$, EDVAN ALVES CHAGAS 6 , \\ SANDRA CÁTIA PEREIRA UCHÔA ${ }^{7}$
}

RESUMO - A produção de mudas de fruteiras nativas é um importante passo para a preservação das espécies, exploração comercial sustentável e geração de emprego. Neste contexto, os fertilizantes alternativos, como pó de rocha, propiciam a obtenção de um substrato com maior fertilidade, rico em nutrientes, com redução de custos em mão de obra e com a reposição de adubação. O objetivo no presente trabalho foi avaliar o desenvolvimento inicial de mudas de camu-camu (Myrciaria dubia H.B.K. McVaugh) em função de doses de pó de basalto. O experimento foi conduzido em casa de vegetação pertencente ao CCA/UFRR. O delineamento experimental foi o de blocos ao acaso, com cinco repetições, em esquema fatorial $(5 \times 2+1)$, sendo seis doses de pó de basalto $\left(0 ; 0,42 ; 1,04 ; 2,08 ; 4,17 \mathrm{e} 8,33 \mathrm{~g} \mathrm{~kg}^{-1}\right)$, duas granulometrias $(0,05 \mathrm{e} 0,10 \mathrm{~mm} \phi)$ e uma testemunha. Vasos de polietileno de 14 litros foram as unidades experimentais e utilizou-se um Latossolo Amarelo distrófico textura média. A incubação do solo nos vasos teve duração de 120 dias e, após esse período, fez-se o transplante das plântulas. Após seis meses do plantio, foram determinados altura, diâmetro do colo, número de ramos e biomassa seca da parte aérea e de raiz das mudas. A partir destes dados, foram calculados os índices morfológicos. Os tratamentos sem pó de basalto $\left(0 \mathrm{~g} \mathrm{~kg}^{-1}\right)$ e a dose de $0,42 \mathrm{~g} \mathrm{~kg}^{-1}$ produziram mudas de menor qualidade em ambas as granulometrias testadas. As melhores mudas de camu-camu foram obtidas aplicando-se 4,17 e 8,33 $\mathrm{g} \mathrm{kg}^{-1}$ de pó de basalto com a granulometria de $0,05 \mathrm{~mm}$.

Termos de indexação: caçari, fertilizante alternativo, rochagem, propagação.

\section{EFFECT OF LEVEL OF CRUSHED BALSAT IN THE INITIAL DEVELOPMENT OF SEEDLINGS OF CAMU-CAMU (Myrciaria dubia H.B.K. McVaugh)}

\begin{abstract}
The seedling production of native fruits is an important step towards the preservation of species, commercial exploitation and sustainable employment generation. In this context, alternative fertilizers, such as rock dust, provide obtaining a substrate with higher fertility, nutrient-rich, with reduced costs in manpower and replacement of fertilization. The objective in the present research was to evaluate the initial development of camu-camu seedlings (Myrciaria dubia H.B.K. McVaugh) in function of levels of crushed basalt. The experiment was carried out in a greenhouse, at CCA/UFRR. The experimental designed was completely randomized with eight treatments and five repetitions in factorial scheme $(5 \times 2+1)$, being five levels of crushed basalt $\left(0,0.42,1.04,2.08,4.17\right.$ and $\left.8.33 \mathrm{~g} \mathrm{~kg}^{-1}\right)$, two particle size $(0.05 \mathrm{~mm}$ and $0.10 \mathrm{~mm} \phi)$. Vases of polyethylene of $14 \mathrm{~L}$ of capacity were the experimental units, and the soil was a Distrofic Yellow Latosol. The incubation period of the soil in vases was for 120 days and after that period the seedlings were transplanted to vases. Six months after the transplant the height, diameter of plant, branches number, and aerial part and root dry biomass of seedlings were determined. From this data the morphologic indexes were calculated. The Treatments without crushed basalt $\left(0 \mathrm{~g} \mathrm{~kg}^{-1}\right)$ and the levels $0.42 \mathrm{~g} \mathrm{~kg}^{-1}$ produced seedlings of lower quality in both granulometry analyzed. The better development of seedlings of camu-camu was obtained using 4.17 e $8.33 \mathrm{~g} \mathrm{~kg}^{-1}$ of crushed basalt with 0.05 granulometry.
\end{abstract}

Index terms: caçari, alternative fertilizer, ground basalt, propagation.

\footnotetext{
1(Trabalho 212-10). Recebido em: 25-10-2010. Aceito para publicação em: 18-07-2011.

${ }^{2} \mathrm{Eng}^{\mathrm{o}}$. Agrônoma, Mestranda do Programa de Pós-Graduação em Agronomia (CCA/UFRR), Campus do Cauamé, BR 174, Km 12 (sentido Pacaraima), Distrito de Monte Cristo, 69310-250, Boa Vista-RR. Bolsista CAPES. Email: mar.kw_yassue@hotmail.com ${ }^{3}$ Eng $^{\circ}$. Agrônomo, D.Sc., Professor Adjunto, Dept ${ }^{\circ}$. de Solos e Engenharia Agrícola, UFRR, Pesquisador do CNPq. Email: valdinar@yahoo.com.br

${ }^{4}$ Eng $^{\circ}$. Agrônomo, D.Sc., Professor Associado, Dept ${ }^{\circ}$. de Fitotecnia, UFV, Av. P.H. Rolfs, Campus Universitário, Viçosa-MG. Bolsista Produtividade em Pesquisa do CNPq. Email: bruckner@uvf.br

${ }^{5}$ Acadêmico do curso de graduação em Agronomia, UFRR, Bolsista de Iniciação Científica (PIBIC/CNPq). Email: htpg_@hotmail.com ${ }^{6}$ Eng $^{\circ}$. Agrônomo, D.Sc., Pesquisador da Embrapa Roraima, BR 174, Km 8, C.P.133, Distrito Industrial, 69301-350, boa Vista-RR. Bolsista Produtividade em Pesquisa do CNPq. Email: echagas@cpafrr.embrapa.br
} 


\section{INTRODUÇÃO}

O método de regeneração da fertilidade do solo, impulsionado com a Revolução Verde, é baseado no emprego de adubos minerais de alta solubilidade e revela-se inviável para a ampla maioria das famílias agricultoras em função de seu alto custo e dos impactos ambientais negativos gerados (ALMEIDA et al., 2007).

Uma alternativa mais ecológica para reposição de nutrientes ao solo em áreas agrícolas é o uso do pó de rocha, um produto adquirido do beneficiamento simples de matérias minerais, de solubilidade mais lenta, que disponibilizam os nutrientes para as plantas por um período maior do que o de fertilizantes convencionais (THEODORO; LEONARDOS, 2006). Em função destas características, os resíduos provenientes da britagem de rochas basálticas têm sido indicados como corretivo da fertilidade de solos (GILLMANN, 1980).

Segundo Theodoro e Leonardos (2006), a rochagem é uma tecnologia que apresenta significativas vantagens econômicas, ambientais e produtivas para as culturas de milho, arroz, mandioca, cana-de-açúcar e hortigranjeiros, quando comparada à adubação com fontes minerais altamente solúveis.

Melamed et al. (2007) destacam que os benefícios advindos da utilização de pós de rocha são: o fornecimento lento de macro e micronutrientes; aumento da disponibilidade desses nutrientes nos solos cultivados; reequilíbrio do $\mathrm{pH}$ do solo e aumento da reserva nutricional do solo.

A fertilização com rochas constitui-se também numa alternativa viável em termos econômicos e ecológicos por não exigir qualquer processo de teor ou ataque químico, pois envolve apenas moagem das rochas usadas na composição do produto, devido à liberação gradual de nutrientes que diminuem as perdas por lixiviação e favorecem uma ação de longo prazo do insumo aplicado (LEONARDOS et al., 2000). A liberação de nutrientes pelo pó de rocha depende tanto do tipo de rocha quanto da superfície de contato da partícula. Está superfície é função do tamanho da partícula, que quanto menor for a partícula, mais a rápida será a reação química, disponibilizando nutrientes (LUCHESE et al., 2002).

$\mathrm{Na}$ tentativa de achar um fertilizante que contenha tanto macro quanto micronutrientes, e principalmente que seja de baixo custo, muitos materiais têm sido testados. Dentre essas alternativas, está a rocha de basalto que, além dessas características citadas, ainda contribui para o aumento do $\mathrm{pH}$ do substrato (KNAPIK, 2005).

O uso sustentável das fruteiras nativas da
Amazônia, com a produção e os beneficiamentos de seus frutos, torna-se uma alternativa viável ao desenvolvimento regional, como fonte de alimentos e meio de agregar valor aos recursos naturais disponíveis na região, melhorando a renda das pequenas comunidades rurais e favorecendo a preservação das espécies nativas. Esses frutos são consumidos sob diferentes formas pelas populações locais e constituem-se, ainda,em uma importante fonte de alimentos para animais silvestres (pássaros, roedores, tatus, canídeos, etc.) e mesmo para o gado (CHAVES, 2003). No entanto, a maioria das espécies frutíferas nativas tem sido aproveitada de maneira extrativista, ou seja, não há preocupação com a propagação e o cultivo comercial dessas espécies, a fim de evitar seu desaparecimento do meio natural.

A formação de mudas constitui-se numa etapa crucial do processo de produção e pode possibilitar aos agricultores a obtenção, em viveiro, de plantas com melhor desempenho para suportar as condições adversas de campo. Expressivos aumentos no crescimento e na qualidade de mudas podem ser alcançados através da fertilização adequada, com reflexos no melhor desenvolvimento, na precocidade e na maior sobrevivência em campo (BARBOSA et al., 2003). O incentivo à produção de mudas de fruteiras nativas é uma importante estratégia para a preservação das espécies, favorecendo a exploração comercial sustentável, gerando emprego e renda para a população local.

O camu-camu ou caçari (Myrciaria dubia (H. B. K.) McVaugh), planta tipicamente amazônica, pertencente à família Myrtaceae, apresenta porte arbustivo e vegeta espontaneamente às margens dos rios e dos lagos, sendo encontrada na estação chuvosa, parcial ou totalmente submersa (VIÉGAS et al., 2004). Seus frutos possuem elevado teor de vitamina $\mathrm{C}$, que combate os radicais livres causadores de envelhecimento e auxilia no fortalecimento do sistema imunológico (MENEZES, 2001).

A produção de frutos de camu-camu adotada pelos caboclos, somente com o extrativismo em ambientes naturais, não garante qualidade, sendo imprescindível a produção de cultivos em terra firme com a vantagem de estender a frutificação e a colheita de frutos com qualidade (GAVINHO, 2005). A adaptação de plantas em terra firme, somada ao manejo adequado e uso de adubações, pode proporcionar maiores condições de desenvolvimento e produção.

Embora a propagação do camu-camu possa ser conduzida com a utilização de métodos assexuados (FERREIRA; GENTIL, 1997), de modo geral, a produção de mudas é realizada basicamente por via sexuada. Assim, recomenda-se obter as sementes de 
plantas sadias, com alta produção e frutos de tamanho homogêneo e no mesmo estágio de maturação, objetivando conseguir maior uniformidade na germinação. Diante da necessidade de incrementar o sistema de produção de camu-camu, no presente trabalho, objetivou-se avaliar as respostas da aplicação de pó de rochas, com duas granulometrias, como fertilizantes alternativos no desenvolvimento inicial de mudas de camu-camu (Myrciaria dubia H.B.K. McVaugh).

\section{MATERIAL E MÉTODOS}

$\mathrm{O}$ experimento foi instalado em casa de vegetação do Centro de Ciências Agrárias da Universidade Federal de Roraima, município de Boa Vista - RR (2 $52^{\prime} 15,49^{\prime \prime} \mathrm{N}$ e $\left.60^{\circ} 42^{\prime} 39,89^{\prime \prime} \mathrm{W}\right)$. A classificação climática de Köeppen é do tipo Awi, com duas estações bem definidas, chuvosa (abril-setembro) e seca (outubro-março) (ARAÚJO et al., 2001). A coleta dos frutos de camu-camu foi realizada manualmente, de uma população de plantas encontradas às margens do Rio Cauamé, município de Boa Vista - RR, selecionando frutos maduros de tamanho homogêneo. As sementes foram extraídas e separadas com auxílio de uma peneira, lavadas em água corrente para a retirada dos resíduos de polpa e de casca. Após a seleção, as sementes foram desinfestadas com solução de hipoclorito de sódio e água na proporção 1:4, por 15 minutos. Posteriormente, as sementes foram secas à sombra, sobre papel-jornal, em ambiente ventilado, por um período de 30 horas, visando à perda da umidade superficial. Em seguida, foram armazenadas em sacos plásticos e acondicionadas em recipiente de vidro hermeticamente fechado, à temperatura, em torno de $10^{\circ} \mathrm{C}$. As sementes foram germinadas em tubetes de $125 \mathrm{~cm}^{3}$ contendo como substrato a composição de pó de serra e areia, na proporção de 1:1 em volume.

O pó de rocha foi obtido de rochas basálticas da Formação geológica Apoteri, município de Boa Vista (RR). A rocha foi fragmentada com martelo pedológico e passada em moinho de bolas, em seguida tamisada em um separador vibratório de peneiras para a obtenção dos diâmetros de 0,10 e $0,05 \mathrm{~mm}$. As doses aplicadas foram: 0,$42 ; 1,04 ; 2,08 ; 4,17$ e $8,33 \mathrm{~g} \mathrm{~kg}^{-1}$, usando como referências os valores utilizados para solos nos trabalhos de Dias et al. (2007) e Escosteguy e Klamt (1998), em que os mesmos conseguiram melhorar as características químicas dos solos estudados e atingir o nível máximo de resposta em termo de disponibilidade de nutrientes.

$\mathrm{O}$ pó foi analisado e caracterizado quimicamente por espectrofotometria de plasma (Tabela 1). A caracterização química e física do Latossolo
Amarelo distrocoeso, de textura média (Tabela 2), e do vermicomposto (Tabela 3 ) foi realizada conforme Embrapa (1999).

O delineamento experimental utilizado foi o inteiramente casualizado, com cinco repetições, em esquema fatorial $(2 \times 5+1)$, sendo duas granulometrias $\left(\mathrm{G}_{1}=0,05\right.$ e $\mathrm{G}_{2}=0,10 \mathrm{~mm}$ de diâmetros $)$ e cinco doses de pó de rocha $\left(\mathrm{D}_{1}=0,42 ; \mathrm{D}_{2}=1,04\right.$; $\mathrm{D}_{3}=2,08 ; \mathrm{D}_{4}=4,17$ e $\left.\mathrm{D}_{5}=8,33 \mathrm{~g} \mathrm{~kg}^{-1}\right)$ acrescidas de uma testemunha. No momento da incubação do substrato, adicionou-se o equivalente a $0,058 \mathrm{~g} \mathrm{~kg}^{-1}$ de $\mathrm{P}_{2} \mathrm{O}_{5}$, tendo como fonte o superfosfato triplo e o pó de granito, como fonte de $\mathrm{K}$, na dosagem de $1,04 \mathrm{~g} \mathrm{~kg}^{-1}$, com granulometria de $0,05 \mathrm{~mm}$, em cada parcela, incluindo a testemunha.

As parcelas foram constituídas por vasos de polietileno preto, com capacidade para 14 litros de substrato. $\mathrm{O}$ substrato foi formado da composição de $20 \%$ de vermicomposto e $80 \%$ de solo, coletado na profundidade de $0-20 \mathrm{~cm}$. A incubação do solo com o pó de rocha foi feita por um período de 120 dias, correspondendo aos meses de janeiro a abril. Após este período, realizou-se o transplante de duas plântulas de camu-camu para cada parcela (vaso de polietileno preto de 14 litros), e após oito dias foi deixada, em cada vaso, a muda mais vigorosa, totalizando cinco plantas por unidade experimental. A irrigação dos vasos foi realizada diariamente para manter a condição de umidade na capacidade de campo, em função do peso dos vasos.

A avaliação do crescimento das mudas foi realizada mensalmente, a partir do primeiro mês após o transplante das plântulas, onde se realizaram as medições de altura, diâmetro de colo e número de ramos em todas as unidades de observações. Para as medições de comprimento, utilizou-se uma régua milimetrada, medindo a partir do nível do substrato até a ponta da última gema apical; enquanto o diâmetro de colo foi determinado no nível do substrato, com auxílio de um paquímetro digital.

Ao final de seis meses da condução do experimento, fizeram-se a avaliação da biomassa seca da parte aérea, biomassa seca de raízes e biomassa seca total das mudas. A partir destas informações, foram avaliadas as relações biomassa seca da raiz e biomassa seca da parte aérea (BSR/BSPA), relação altura da parte aérea e diâmetro do colo (ALT/ $\mathrm{DM})$, relação altura da parte aérea e biomassa seca da parte aérea (ALT/BSPA) e o índice de qualidade de Dickson (IQD); este foi determinado em função da altura da parte aérea (ALT), do diâmetro do colo (DC), da biomassa seca da parte aérea (BSPA) e da biomassa seca das raízes (BSR), por meio da fórmula (DICKSON et al., 1960): 


$$
I Q D=\frac{B S T}{(A L T / D M)+(B S P A / B S R)}
$$

As mudas foram lavadas sobre uma peneira fina com jatos brandos de água para a remoção do substrato aderido às raízes, com coleta de segmentos de raiz retidos pela peneira. Após esse processo, a muda foi separada em raízes e parte aérea. Secas em estufa com circulação forçada de ar a $65^{\circ} \mathrm{C}$, por 72 horas, e as amostras então foram pesadas separadamente em balança analítica para a determinação da biomassa seca da parte aérea, biomassa seca de raízes e biomassa seca total.

A análise estatística foi realizada com o auxílio do programa SISVAR (FERREIRA, 2005) e SAEG 9.0 (RIBEIRO JÚNIOR; MELO, 2008), aplicando-se a análise de variância através do teste $\mathrm{F}$, e, em seguida, os dados qualitativos foram comparados através do teste de Tukey, e os quantitativos, através de regressão polinomial. Os gráficos foram elaborados com o programa SIGMA PLOT 11.0.

\section{RESULTADOS E DISCUSSÃO}

O número de ramos (NR) e o diâmetro do colo (DC) não foram afetados significativamente pela granulometria $0,05 \mathrm{~mm}$ (Tabela 4). Porém, para a variável altura, as mudas submetidas às doses de 4,17 e $8,33 \mathrm{~g} \mathrm{~kg}^{-1}$ na gralunometria $0,05 \mathrm{~mm} \mathrm{e} 8,33$ $\mathrm{g} \mathrm{kg}^{-1}$ na granulometria $0,10 \mathrm{~mm}$ apresentaram resultados estatisticamente superiores às demais doses de pó de basalto. O tratamento sem pó de basalto $\left(0 \mathrm{~g} \mathrm{~kg}^{-1}\right)$ e a menor dose $\left(0,42 \mathrm{~g} \mathrm{~kg}^{-1}\right)$ produziram mudas de menor porte em ambas as granulometrias (Tabela 4).

A granulometria do pó de basalto influenciou significativamente na altura das mudas (ALT) de camu-camu. Aquelas submetidas a aplicações que utilizaram menor granulometria do material $(0,05$ $\mathrm{mm}$ ) apresentaram maior desenvolvimento vertical comparado àquelas produzidas com granulometria de $0,10 \mathrm{~mm}$. Tal efeito decorreu em função da maior disponibilidade de nutrientes ao solo pelo pó de basalto com granulometria menor, o que contribuiu substancialmente para aumentar a Soma de Bases (SB), o complexo de troca (CTC) e o $\mathrm{pH}$, reduzindo o efeito do $\mathrm{Al}^{+3}$ no substrato e permitindo que as mudas apresentassem melhor desenvolvimento vegetativo.

A variável ALT (Tabela 4) foi influenciada com o aumento das doses, em que se observou incremento de $46,57 \%$ e $57,62 \%$ entre as dose de 8,33 e $0,42 \mathrm{~g} \mathrm{~kg}^{-1}$ das respectivas granulometrias
$(0,05$ e $0,10 \mathrm{~mm})$. Observou-se também que as doses com granulometria mais fina $(0,05 \mathrm{~mm})$ foram estatisticamente superiores às doses da granulometria mais grossa $(0,10 \mathrm{~mm})$. A maior disponibilidade de nutrientes obtida com a utilização de pó de basalto mais fino pode ser o fator que proporcionou melhor desenvolvimento em altura das mudas de camu-camu.

O comportamento das doses para a variável diâmetro do colo foi semelhante ao da variável altura, em que a menor dose, $0,42 \mathrm{~g} \mathrm{~kg}^{-1}$, das duas granulometrias produziram mudas menores e com diâmetro do colo mais fino, porém não houve diferença estatística significativa entre as doses de granulometria $0,05 \mathrm{~mm}$. No entanto, a resposta das mudas submetidas às doses de pó de basalto mais fino $(0,05 \mathrm{~mm})$ tende a serem maiores na medida em que as doses aumentam. Porém, para a granulometria $0,10 \mathrm{~mm}$, observou-se um aumento do diâmetro com o incremento entre as doses mínima e máxima. A dose $8,33 \mathrm{~g} \mathrm{~kg}^{-1}$ produziu mudas com 4,86 mm de diâmetro, enquanto os tratamentos com $0,42 \mathrm{~g} \mathrm{~kg}^{-1}$, mudas com 3,04 mm, indicando um incremento de $37 \%$ (Tabela 4 ).

O número de ramos não apresentou diferença significativa, no entanto as mudas da testemunha e das doses de 0,42 e 1,04 $\mathrm{g} \mathrm{kg}^{-1}$ produziram mais ramos em relação às demais doses, independentemente da granulometria. Esse efeito ocorreu, provavelmente, devido à quebra da dominância apical pela morte das ponteiras dos ramos, sintoma característico de deficiência de $\mathrm{Ca}$, favorecendo o surgimento de ramos laterais. As mudas dos tratamentos 2,08; 4,17 e 8,33 $\mathrm{g} \mathrm{kg}^{-1}$ de pó de basalto não apresentaram morte de ponteiros, o que pode estar associado à maior disponibilidade de nutrientes pela rocha, principalmente $\mathrm{Ca}$ (Tabela 4).

As doses de $0 ; 0,42$ e 1,04 $\mathrm{g} \mathrm{kg}^{-1}$ proporcionaram maior ramificação em relação às demais doses. É notável a inversão no comportamento dessas doses, onde inicialmente a emissão de ramos foi menor e elas passaram a superar as demais doses a partir dos 90 dias após o transplante. No entanto, não se observou morte dos ponteiros nas doses de 2,08; 4,17 e $8,33 \mathrm{~g} \mathrm{~kg}^{-1}$, sendo que os ramos emitidos pelas mudas submetidas a essas doses se mantiveram em desenvolvimento até o final da avaliação.

Folhas mais jovens e outros tecidos novos desenvolvem sintomas de deficiência de Ca pela baixa retranslocação na planta (DECHEN; NACHTIGALL, 2007). Os tecidos novos precisam de Ca para a formação de suas paredes celulares. Portanto, a deficiência de Ca caracteriza-se pelo fato de a planta apresentar as nervuras das folhas e os pontos de crescimento de forma gelatinosa e, em casos severos, os pontos de crescimento morrem. Fundamentado nestas informações, foi possível observar deficiência de cálcio nas 
plantas dos tratamentos com menores doses de pó de rocha, em que as folhas novas ficaram retorcidas e enroladas para a sua face ventral, sendo que os mesmos sintomas foram observados por Viégas et al. (2004) ao avaliarem o efeito da omissão de macronutrientes no crescimento, nos sintomas de deficiências nutricionais, assim como na composição mineral em plantas de camu-camuzeiro.

A resposta às doses de pó de basalto em ALT foi mais bem descrita pelo método quadrático (Figura 1 A e B). A dose de máxima eficiência técnica (MET) para ALT foi obtida na dose de 7,68 e 7,29 $\mathrm{g} \mathrm{kg}^{-1}$ nas granulometrias 0,05 e $0,10 \mathrm{~mm}$, respectivamente. Já para a variável DC, a resposta às doses de pó de basalto foi mais bem descrita pelo modelo linear e quadrático, nas granulometrias 0,05 e $0,10 \mathrm{~mm}$, respectivamente. A dose $\mathrm{MET}$ obtida em resposta à granulometria mais grossa $(0,10 \mathrm{~mm})$ foi na dose de $7,22 \mathrm{~g} \mathrm{~kg}^{-1}$.

Os valores de BSPA, BSR e BST foram crescentes, com diferenças significativas entre doses e entre as granulometrias. Os maiores valores de BSPA foram obtidos utilizando-se da dose de $8,33 \mathrm{~g} \mathrm{~kg}^{-1}$ com 11,1 g e 6,24 g, na granulometria 0,05 mm e $0,10 \mathrm{~mm}$, respectivamente (Tabela 5). Esses resultados superam o encontrado por Suguino (2006), que obteve BSPA de 0,18 g e BSR 0,09 g em mudas de camu-camu, avaliando diferentes substratos. No entanto, os dados obtidos por Viégas et al. (2004) foram superiores, com 63,44 g de BSPA e 32,73 g de BSR ao avaliar o efeito da omissão de macronutrientes em mudas de camu-camu.

Estudando BSPA e BSR entre as granulometrias, notou-se que, de forma geral, a $0,05 \mathrm{~mm}$ foi melhor em relação a $0,10 \mathrm{~mm}$, que pode ser resultante da disponibilidade dos nutrientes ao substrato ter sido mais rápida da granulometria mais fina. Assim, nas menores doses e na ausência do pó de basalto, os incrementos de biomassa seca são menores, fato que pode ser explicado pela baixa disponibilidade de nutrientes, como o cálcio, o qual tem relação direta com o crescimento de meristema, estimulando o crescimento e o funcionamento apropriado dos ápices radiculares, aumentando, assim, a BSR das mudas; o magnésio tem papel estrutural como componente da molécula de clorofila, sendo que os sintomas de deficiência são clorose e queda das folhas (DECHEN; NACHTIGALL, 2007), proporcionando a redução da eficiência fotossintética das mudas e a produção de fotoassimilados, comprometendo seu crescimento.

Outro fator que possivelmente limitou o desenvolvimento radicular das mudas produzidas nas menores doses de pó de basalto foi a presença do $\mathrm{Al}^{+3}$, que teve maior disponibilidade nestes tratamentos durante o ensaio devido a condições de $\mathrm{pH}$ mais ácido no substrato. Assim, os solos que contêm teores elevados de $\mathrm{Al}^{+3}$, como é o caso do solo utilizado no ensaio, podem apresentar limitações ao bom desenvolvimento e crescimento radicular das plantas e, consequentemente, à parte aérea (DECHEN et al., 2007).

A resposta das mudas de camu-camu às doses de pó de rocha na produção de BSPA e BSR foi mais bem descrita pelo modelo quadrático (Figura 2 A e B), no qual as doses que produziram mudas com maiores valores de biomassa seca também foram aquelas que resultaram em maiores alturas. Verificou-se que a dose de $8,33 \mathrm{~g} \mathrm{~kg}^{-1}$ em ambas as granulometrias produziram mudas com BST superior às demais doses, bem como BSPA e BSR.

Os índices morfológicos das mudas de camucamu, calculados a partir das variáveis analisadas (Tabela 6), mostram que as menores relações BSPA/ BSR foram obtidas na testemunha e na doses de $0,42 \mathrm{~g} \mathrm{~kg}^{-1}$ da granulometria $0,10 \mathrm{~mm}$. Não houve diferença estatística entre as doses da granulometria 0,05 mm, no entanto observou-se que a tendência dos resultados de BSPA/BSR é de serem maiores à medida que as doses aumentam. Esses resultados podem estar relacionados ao hábito de crescimento dessa espécie que prioriza o crescimento da parte aérea, e não necessariamente o menor desenvolvimento do sistema radicular. No entanto, as menores relações BSPA/BSR obtidas na ausência de pó de basalto e na dose de $0,42 \mathrm{~g} \mathrm{~kg}^{-1}$ sugerem que a baixa disponibilidade de nutrientes pode ter causado a redução do desenvolvimento do sistema radicular e, consequentemente, diminuição significativa da absorção de $\mathrm{H}_{2} \mathrm{O}$ e nutrientes das camadas subsuperficiais do solo.

A relação ALT/BSPA indica o quanto lignificado estão as mudas, ou seja, o quanto de BSPA as mudas produzem à medida que crescem. Segundo Gomes e Paiva (2004), quanto menor o seu valor, maior a chance de sobrevivência das mudas no campo. A dose de $8,33 \mathrm{~g} \mathrm{~kg}^{-1}$ proporcionou obtenção de mudas com menor relação ALT/BSPA, sendo 7,95 e 13,34 nas granulometrias $0,05 \mathrm{~mm}$ e $0,10 \mathrm{~mm}$, respectivamente. $\mathrm{O}$ contrário ocorreu nas mudas submetidas ao tratamento sem utilização de pó de basalto, que apresentou maior relação ALT/BSPA, sendo 25,17 e 31,01 nas granulometrias 0,05 $\mathrm{mm}$ e $0,10 \mathrm{~mm}$, respectivamente. Esses resultados indicam que o tratamento com aplicação de $8,33 \mathrm{~g} \mathrm{~kg}^{-1}$ de pó de basalto proporcionou mudas mais lignificadas e que têm maiores chances de sobreviverem quando implantadas em campo. Desta forma, as mudas obtidas na granulometria mais fina $(0,05 \mathrm{~mm})$ produ- 
ziram mais biomassa seca da parte aérea, verificada pela média do índice ALT/BSPA, que foi inferior à média da granulometria 0,10 .

A relação ALT/DM, resultante da divisão da altura das mudas pelo seu respectivo diâmetro de colo, é considerada uma relação de extrema importância, pois fornece indicações de quanto delgada está a muda e revela se existe equilíbrio no crescimento. Quanto menor o seu valor, maior a chance de sobrevivência e estabelecimento no local de plantio (GOMES; PAIVA, 2004). As doses 0 e $0,42 \mathrm{~g} \mathrm{~kg}^{-1}$ proporcionaram menores valores de ALT/DM, o que pode sugerir melhor condição de sobrevivência. No entanto, esses resultados estão mais associados ao baixo crescimento da parte aérea, o que causa a redução da relação. Essa resposta está relacionada com a baixa disponibilidade de nutrientes dos tratamentos, o que comprometeu o crescimento, principalmente da parte aérea.

O IQD é apontado como bom indicador de qualidade de mudas e é utilizado para o cálculo da robustez (relação ALT/DM) e o equilíbrio da distribuição da biomassa (relação BSPA/BSR). Quanto maior o IQD, melhor é a qualidade da muda produzida, em que o valor 0,20 representa o valor mínimo (GOMES; PAIVA, 2004). Assim, na avaliação desse índice nas mudas de camu-camu, observou-se que, na granulometria de $0,05 \mathrm{~mm}$, houve diferença significativa para a dose de $8,33 \mathrm{~g} \mathrm{~kg}^{-1}$ com IQD de 0,93 , seguida das doses 2,08 e $4,17 \mathrm{~g} \mathrm{~kg}^{-1}$ com IQD de 0,62 e 0,74 , respectivamente, na granulometria de $0,05 \mathrm{~mm}$ (Tabela 6 ). Já na granulometria $0,10 \mathrm{~mm}$, não houve diferença significativa entre as doses. No entanto, houve tendência de os resultados de IQD serem maiores em 4,17 e $8,33 \mathrm{~g} \mathrm{~kg}^{-1}$, demonstrando que as mudas submetidas às maiores doses de pó de basalto são de melhor qualidade em relação àquelas produzidas nas doses menores. Knapik (2005) obteve IQD que variou de 0,04 a 0,18 em mudas de Prunus sellowii com o uso do pó de basalto, não atingindo o mínimo estabelecido: 0,20.

TABELA 1 - Teores de macro e micronutrientes ${ }^{1}$ em amostras de pó de basalto e de pó de granito. Valores médios \pm desvio-padrão $(\mathrm{n}=3)$

\begin{tabular}{|c|c|c|}
\hline \multirow{2}{*}{ Macronutriente (mg dm ${ }^{-3}$ ) } & \multicolumn{2}{|c|}{ Amostra } \\
\hline & Pó de basalto & Pó de granito \\
\hline Cálcio & 9.700 & - \\
\hline Magnésio & 4.800 & - \\
\hline Potássio & 48 & - \\
\hline Fósforo & 520 & - \\
\hline Enxofre & 14 & - \\
\hline \multicolumn{3}{|l|}{ Micronutriente (mg kg-1) } \\
\hline Cobalto & $45,48 \pm 2,43$ & $1,68 \pm 0,38$ \\
\hline Cobre & $218,82 \pm 1,27$ & $101,06 \pm 8,82$ \\
\hline Manganês & $1033,95 \pm 16,08$ & $233,90 \pm 4,39$ \\
\hline Molibdênio & $2<0,05$ & $1,78 \pm 0,16$ \\
\hline Zinco & $79,70 \pm 0,75$ & $48,68 \pm 1,93$ \\
\hline
\end{tabular}

${ }^{1}$ Método USEPA 3052.

${ }^{2}$ Valores precedidos do sinal $<$ referem-se ao limite de quantificação do método analítico.

TABELA 2 - Características químicas, carbono orgânico (CO) e relação $\mathrm{C} / \mathrm{N}$ do vermicomposto.

\begin{tabular}{|c|c|c|c|c|c|c|c|c|c|}
\hline pH & K & $\mathbf{P}$ & $\mathbf{N}^{* *}$ & $\mathrm{Ca}$ & Mg & $\mathbf{F e}$ & $\mathrm{Zn}$ & $\mathbf{C O}^{* * * *}$ & \\
\hline $\mathrm{H}_{2} \mathrm{O}$ & \multicolumn{5}{|c|}{--------dag kg ${ }^{-1}$----------- } & \multicolumn{2}{|c|}{----ppm--- } & $\%$ & $\mathrm{C} / \mathrm{N}$ \\
\hline 5,05 & 0,32 & 0,24 & 1,68 & 0,60 & 0,26 & 1522 & 246 & 23,24 & 13,83 \\
\hline
\end{tabular}

* Teores totais determinados no extrato ácido (ácido nítrico com ácido perclórico).

** Método do Kjeldahl. *** Método Walkley-Black

TABELA 3 - Características químicas e textural do solo antes da instalação do experimento.

\begin{tabular}{ccccccccccc}
\hline $\mathbf{p H}$ & $\mathbf{K}$ & $\mathbf{P}$ & $\mathbf{C a}+\mathbf{M g}$ & $\mathbf{A l}^{3+}$ & $\mathbf{S B}$ & $\mathbf{T}$ & $\mathbf{M O}$ & Argila & Silte & Areia \\
\hline $\mathbf{H}_{\mathbf{2}} \mathbf{O}$ & $--\mathbf{m g ~ d m}^{-3}--$ & \multicolumn{2}{c}{$-----\mathbf{~ c m o l ~}_{\mathbf{c}} \mathbf{d m}^{-3}------$} & $\mathbf{\%}$ & $-----\mathbf{d a g}_{\mathbf{~ k g}}$ & ----- \\
\hline 4,8 & 15 & 0,1 & 0,8 & 0,9 & 0,84 & 3,7 & 1,7 & 250 & 150 & 600 \\
\hline
\end{tabular}


TABELA 4 - Altura da muda (ALT), diâmetro do colo (DM) e número de ramos (NR) das mudas de camucamu em função de doses de pó de basalto e diferentes granulometrias. Boa Vista-RR (2009).

\begin{tabular}{|c|c|c|c|c|c|c|}
\hline \multirow{3}{*}{ Dose $\left(\mathrm{g} \mathrm{kg}^{-1}\right)$} & \multicolumn{2}{|c|}{ ALT (cm) } & \multicolumn{2}{|c|}{ DM (mm) } & \multicolumn{2}{|c|}{ NR } \\
\hline & \multicolumn{6}{|c|}{ Granulometria (mm) } \\
\hline & $\mathbf{0 , 0 5}$ & $\mathbf{0 , 1 0}$ & 0,05 & $\mathbf{0 , 1 0}$ & 0,05 & $\mathbf{0 , 1 0}$ \\
\hline 0 & $39,52 \mathrm{~d} \mathrm{~A}$ & $27,56 \mathrm{c} \mathrm{B}$ & 4,12 a $\mathrm{A}$ & $2,80 \quad \mathrm{c} \mathrm{B}$ & 3 a A & 3 a A \\
\hline 0,42 & $47,02 \mathrm{~d} \mathrm{~A}$ & 29,74 с B & 4,40 a $\mathrm{A}$ & 3,04 bc B & 3 a A & 3 a A \\
\hline 1,04 & 70,10 с A & 49,22 b B & 4,44 a A & 3,64 abc A & 3 a A & 3 a A \\
\hline 2,08 & $71,40 \mathrm{bc} \mathrm{A}$ & 51,98 b B & 4,50 a $\mathrm{A}$ & 3,66 abc A & 2 a A & 2 a A \\
\hline 4,17 & $78,90 \mathrm{~b} \mathrm{~A}$ & 65,56 a B & 5,08 a A & $4,60 \mathrm{ab} A$ & 2 a A & 2 a A \\
\hline 8,33 & 88,00 a A & 70,18 a B & 5,48 a A & 4,86 a A & $2 \mathrm{aA}$ & 2 a A \\
\hline CV (\%) & 7,9 & & & & & 25 \\
\hline
\end{tabular}

Médias seguidas pela mesma letra, maiúscula na horizontal e minúscula na vertical, não diferem entre si, pelo teste de Tukey, ao nível de significância de $5 \%$.

TABELA 5 - Biomassa seca da parte aérea (BSPA), biomassa seca de raízes (BSR), biomassa seca total (BST) das mudas de camu-camu em função de doses de pó de basalto e diferentes granulometrias. Boa Vista-RR (2009).

\begin{tabular}{|c|c|c|c|c|c|c|}
\hline \multirow{3}{*}{ Dose $\left(\mathrm{g} \mathrm{kg}^{-1}\right)$} & \multicolumn{2}{|c|}{ BSPA (g) } & \multicolumn{2}{|c|}{ BSR (g) } & \multicolumn{2}{|c|}{ BST (g) } \\
\hline & \multicolumn{6}{|c|}{ Granulometria (mm) } \\
\hline & 0,05 & $\mathbf{0 , 1 0}$ & 0,05 & 0,10 & $\mathbf{0 , 0 5}$ & $\mathbf{0 , 1 0}$ \\
\hline 0 & $1,63 \mathrm{cA}$ & 0,99 с A & 1,22 c A & 1,13 a $\mathrm{A}$ & $2,85 \mathrm{~d} A$ & $2,13 \mathrm{~b} \mathrm{~A}$ \\
\hline 0,42 & $2,59 \mathrm{c} \mathrm{A}$ & $1,03 \mathrm{cA}$ & 1,74 bc A & 1,23 a $\mathrm{A}$ & $4,32 \mathrm{~cd} \mathrm{~A}$ & $2,27 \mathrm{~b} \mathrm{~A}$ \\
\hline 1,04 & 4,31 bc A & $1,85 \mathrm{bc} \mathrm{A}$ & 2,61 bc A & 1,82 a $\mathrm{A}$ & 6,92 bcd $A$ & $3,66 \mathrm{ab} A$ \\
\hline 2,08 & 7,09 b A & $2,81 \mathrm{abcB}$ & 3,81 abc $A$ & 1,54 a B & 10,9 abc $\mathrm{A}$ & $4,35 \mathrm{ab} B$ \\
\hline 4,17 & 7,59 abA & 5,35 ab A & 4,27 ab A & 3,05 a $\mathrm{A}$ & 11,9 ab A & 8,39 ab A \\
\hline 8,33 & 11,1 a A & 6,24 a B & 5,63 a $\mathrm{A}$ & 3,54 a B & 16,8 a $\mathrm{A}$ & 9,78 a B \\
\hline CV (\%) & \multicolumn{2}{|c|}{49,05} & \multicolumn{2}{|c|}{57,97} & \multicolumn{2}{|c|}{50,69} \\
\hline
\end{tabular}

Médias seguidas pela mesma letra, maiúscula na horizontal e minúscula na vertical, não diferem entre si, pelo teste de Tukey, ao nível de significância de 5\%.

TABELA 6 - Índices morfológicos das mudas de camu-camu em função de doses de pó de basalto e diferentes granulometrias. Boa Vista-RR (2009).

\begin{tabular}{|c|c|c|c|c|c|c|c|c|}
\hline \multirow{3}{*}{$\begin{array}{c}\text { Dose } \\
\left(\mathrm{g} \mathrm{kg}^{-1}\right)\end{array}$} & \multicolumn{2}{|c|}{ BSPA/BSR } & \multicolumn{2}{|c|}{ ALT/BSPA } & \multicolumn{2}{|c|}{ ALT/DM } & \multicolumn{2}{|c|}{ IQD } \\
\hline & \multicolumn{8}{|c|}{ Granulometria (mm) } \\
\hline & 0,05 & $\mathbf{0 , 1 0}$ & 0,05 & $\mathbf{0 , 1 0}$ & 0,05 & 0,10 & 0,05 & 0,10 \\
\hline 0 & 1,42 a $\mathrm{A}$ & $0,87 \mathrm{~b} \mathrm{~A}$ & 25,17 a A & 31,01 a A & $10,38 \mathrm{~b} \mathrm{~A}$ & $9,91 \mathrm{~b} \mathrm{~A}$ & $0,27 \mathrm{~b} \mathrm{~A}$ & 0,20 a $\mathrm{A}$ \\
\hline 0,42 & 1,57 a $A$ & 0,89 b B & 21,19 a $\mathrm{A}$ & $30,77 \mathrm{ab} A$ & $11,61 \mathrm{~b} \mathrm{~A}$ & $9,98 \mathrm{~b} \mathrm{~A}$ & $0,33 \mathrm{~b} \mathrm{~A}$ & 0,21 a $A$ \\
\hline 1,04 & 1,87 a $A$ & $1,53 \mathrm{ab} A$ & 16,72 a $A$ & $28,48 \mathrm{ab} A$ & 15,81 a A & $13,7 \mathrm{ab} A$ & $0,39 \mathrm{~b} \mathrm{~A}$ & 0,26 a $A$ \\
\hline 2,08 & 1,93 a $\mathrm{A}$ & $1,74 \mathrm{ab} A$ & 16,22 a $A$ & $27,67 \mathrm{ab} A$ & 15,91 a $\mathrm{A}$ & 14,3 a $\mathrm{A}$ & $0,62 \mathrm{ab} A$ & 0,28 a $A$ \\
\hline 4,17 & 2,00 a A & $1,74 \mathrm{ab} A$ & 12,72 a $A$ & $13,61 \mathrm{ab} A$ & 16,09 a A & 14,5 a $\mathrm{A}$ & $0,74 \mathrm{ab} A$ & 0,54 a $A$ \\
\hline 8,33 & 2,02 a A & 1,98 a A & 7,95 a A & $13,34 \mathrm{~b} \mathrm{~A}$ & 16,16 a $\mathrm{A}$ & 14,6 a $\mathrm{A}$ & 0,93 a $\mathrm{A}$ & $0,60 \mathrm{a} \mathrm{A}$ \\
\hline CV (\%) & & 35 & &, 78 & 15 & & 59 & \\
\hline
\end{tabular}

Médias seguidas pela mesma letra, maiúscula na horizontal e minúscula na vertical, não diferem entre si, pelo teste de Tukey, ao nível de significância de $5 \%$. 

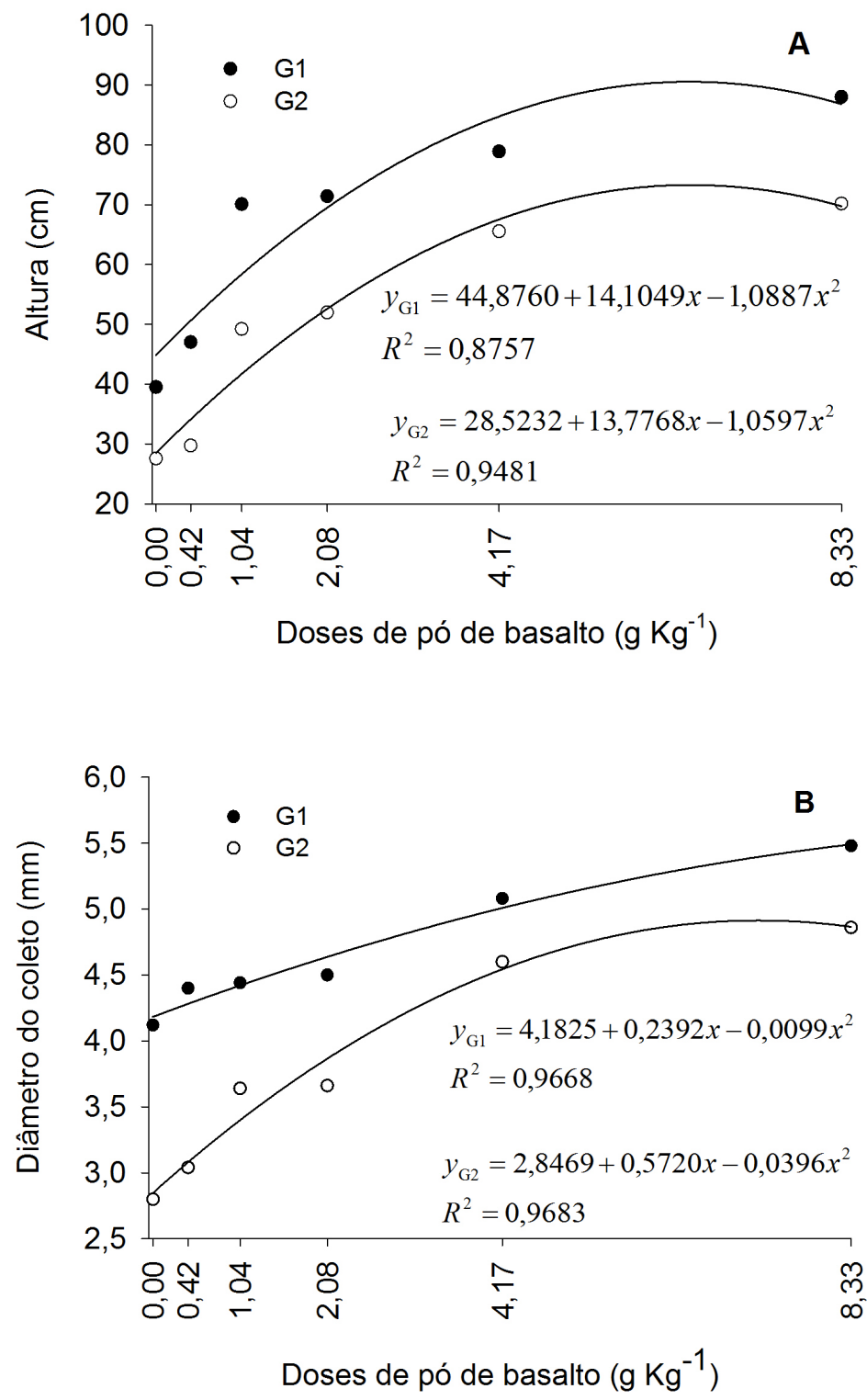

FIGURA 1 - Altura (A) e diâmetro do colo (B) das mudas de camu-camu em função de doses de pó de basalto e diferentes granulometrias ( $\mathrm{G} 1=0,05 \mathrm{~mm}$ e $\mathrm{G} 2=0,10 \mathrm{~mm})$. Boa Vista-RR (2009). 

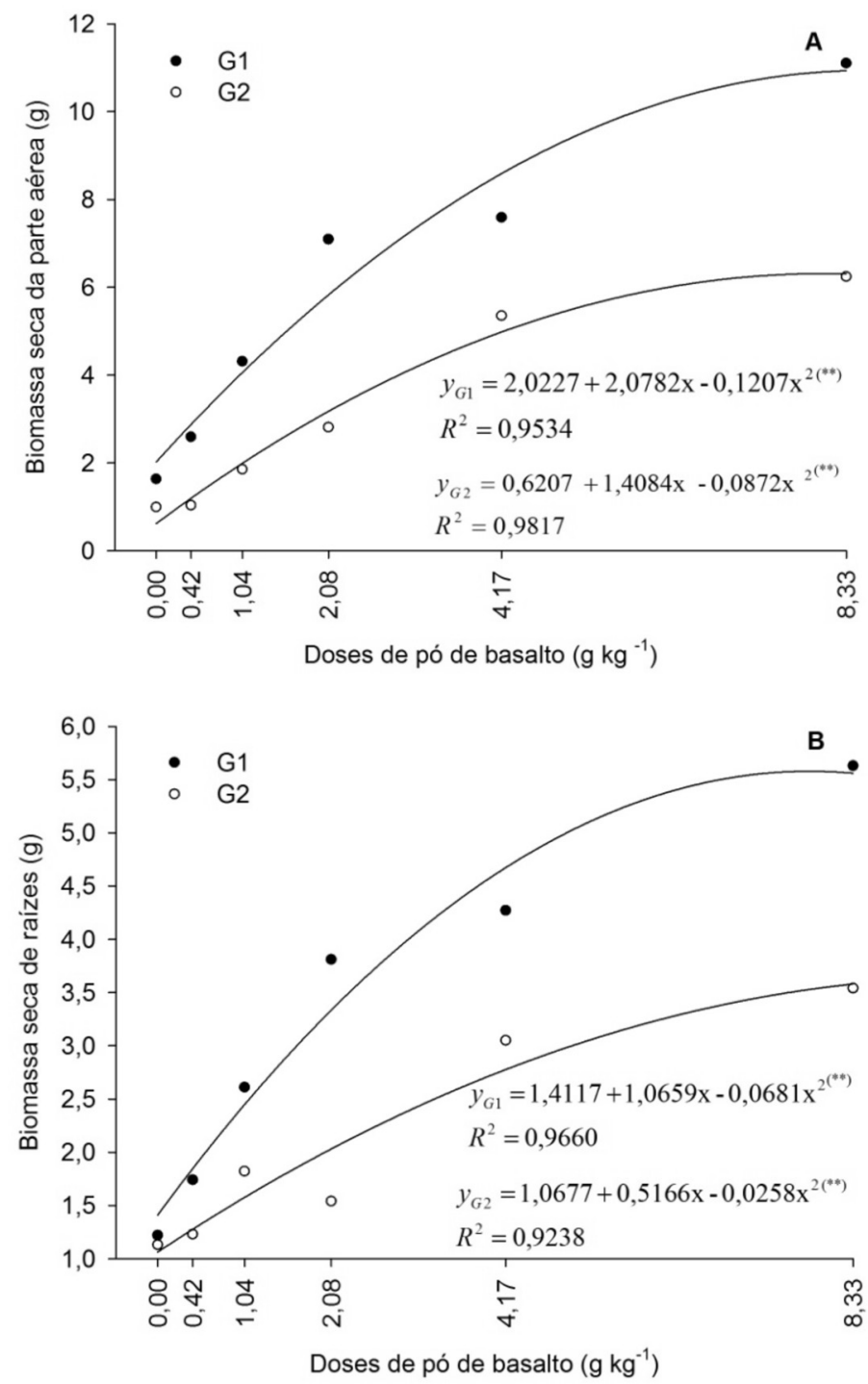

FIGURA 2 - Biomassa seca da parte aérea - BSPA (A) e biomassa seca das raízes - BSR (B) das mudas de camu-camu sob doses de pó de basalto e diferentes granulometrias $(\mathrm{G} 1=0,05 \mathrm{~mm}$ e $\mathrm{G} 2=$ 0,10mm). Boa Vista-RR (2009).

\section{CONCLUSÕES}

1-Os tratamentos sem pó de basalto $\left(0 \mathrm{~g} \mathrm{~kg}^{-1}\right)$ e a dose de $0,42 \mathrm{~g} \mathrm{~kg}^{-1}$ produzem mudas de menor qualidade em ambas as granulometrias testadas.

2-As melhores mudas de camu-camu são obtidas aplicando-se 4,17 e $8,33 \mathrm{~g} \mathrm{~kg}^{-1}$ de pó de basalto com a granulometria de $0,05 \mathrm{~mm}$.

\section{REFERÊNCIAS}

ALMEIDA, E.; SILVA, F.J.P.; RALISCH, R. Revitalização dos solos em processos de transição agroecológica no Sul do Brasil. Revista Agriculturas: Experiências em Agroecologia, Rio de Janeiro, v.4, n.1, p.7-10, 2007.

ARAÚJO, W.F.; ANDRADE JÚNIOR, A.S.; MEDEIROS, R.D.; SAMPAIO, R.A. Precipitação pluviométrica provável em Boa Vista, Estado de Roraima, Brasil. Revista Brasileira de Engenharia Agrícola e Ambiental, Campina Grande, v.5, n.3, p.563-567, 2001. 
DECHEN, A. R.; NACHTIGALL, G. R. Elementos Requeridos à Nutrição de Plantas. In: NOVAIS, R. F; ALVAREZ, V. H. V.; BARROS, N. F. de; FONTES, R. L. F.; CANTARUTTI, R. B.; NEVES, J. C. Fertilidade do solo. Viçosa, MG: Sociedade Brasileira de Ciência do Solo, 2007. p. 91-128.

DIAS, F. O.; MELO, V. F.; UCHÔA, S. C. P.; CARVALHO, K. S.; SILVA, S. M. Pó do basalto Apoteri nas propriedades químicas de um Latossolo Amarelo distrófico. In: CONGRESSO BRASILEIRO DE CIÊNCIA DO SOLO, 31., 2007, Gramado. Anais... CD ROM.

DICKSON, A.; LEAF, A. L.; HOSNER, J. F. Quality appraisal of white spruce and white pine seedling stock in nurseries. Forestry Chronicle, Ottawa, v. 36, p. 10-13, 1960.

EMBRAPA. Manual de análises de solos, plantas e fertilizantes. Brasília: Embrapa Comunicação para Transferência de Tecnologia, 1999. p. 171-222.

ESCOSTEGUY, P. A.V.; KLAMT, E. Basalto moído como fonte de nutriente. Revista Brasileira de Ciência do Solo, Viçosa, MG, v.22, p.11-20, 1998.

FERREIRA, DF. Estatística básica. Lavras: Editora UFLA, 2005. 676 p.

FERREIRA, S.A.N.; GENTIL, D.F.O. Propagação assexuada do camu-camu (Myrciaria dubia) através de enxertias do tipo garfagem. Acta Amazônica, Manaus, v.27, n.3, p.163-168, 1997.

GAVINHO, C. A. Efeitos da adubação foliar na produção de frutos e na concentração de ácido ascórbico do camu-camu (Myrciaria dúbia (H.B.K.) McVaugh) em condições de terra-firme. 2005. Dissertação (Mestrado) - Instituto Nacional de Pesquisas da Amazonia, Universidade Federal da Amazônia, Manaus, 2005.

GILLMAN, G.P. The effect of crushed basalt scoria on the cation exchange properties of highly weathered soil. Soil Science Society America Journal, Madison, v.44, p.465-468, 1980.
KNAPIK, J. G. Utilização do pó de basalto como alternativa à adubação convencional na produção de mudas de Mimosa scabrella Benth e Prunus sellowii Koehne. 2005. 163f. Dissertação (Mestrado em Ciências Florestais) - Universidade Federal do Paraná, Curitiba, 2005.

LEONARDOS, O.H.; THEODORO, S.C.H.; ASSAD, M.L. Remineralization for sustainable agriculture: a tropical perspective from a brasilian viewpoint. Nutrient Cycling in Agroecosystems, Dordrecht, v.56, p.3-9, 2000.

LUCHESE, E. B.; FAVERO, L. O. B.; LENZI, E. Fundamentos da química do solo, teoria e prática. 2. ed. Rio de Janeiro: Freitas Bastos, 2002. 182p.

MELAMED, R.; GASPAR, J.C.; MIEKELEY, N. Pó-de-rocha como fertilizante alternativo para sistemas de produção sustentáveis em solos tropicais. (Série estudos e documentos, 72). Disponível em: $<$ http://www.cetem.gov.br/serie_sed.htm $>$. Acesso em: 09 jul. 2007.

MENEZES, H. C. de. Saudável Camu-camu. Pesquisa FAPESP, São Paulo, p. 64-65, 2001.

RIBEIRO JÚNIOR, J. I.; MELO, A. L. P. Guia prático para utilização do SAEG. Viçosa, MG: UFV, 2008. 288 p.

SUGUINO, E. Influência dos substratos no desenvolvimento de mudas de plantas frutíferas. 2006. 81 f. Tese (Doutorado) - Escola Superior de Agricultura “Luiz de Queiroz”, Universidade de São Paulo, Piracicaba, 2006.

THEODORO, S.H.; LEONARDOS, O.H. The use of rocks to improve family agriculture in Brazil. Anais da Academia Brasileira de Ciências, Rio de Janeiro, v. 78, n.4, 721-730, 2006.

VIÉGAS, I. J. M.; THOMAZ, M. A. A.; SILVA, J. F. da; CONCEIÇÃ̃, H. E. O. da; NAIFF, A. P. M. Efeito da omissão de macronutrientes e boro no crescimento, nos sintomas de deficiências nutricionais e na composição mineral de plantas de camucamuzeiro. Revista Brasileira de Fruticultura, Jaboticabal, v.26, n.2, p.315-319, 2004. 